\title{
Comprehensive Evaluation and Case Study of Scientific and Technological Innovation Ability of Colleges and Universities Based on Multi-level Gray Correlation Analysis Method
}

\author{
Li Wang ${ }^{1, a}$, Chuanghong $\mathrm{Li}^{2, b}$ \\ ${ }^{1}$ School of Traffic and Transportation, Lanzhou Jiaoton University, Lanzhou 730070, China \\ ${ }^{2}$ Lanzhou Jiaotong University Engineering Consultation Co.Ltd, Lanzhou 730070, China \\ a41513044@qq.com, b546345618@qq.com
}

Keywords: Gray correlation analysis, scientific and technological innovation in colleges and universities, comprehensive evaluation, example.

\begin{abstract}
Scientific and technological innovation in colleges and universities occupies a very important position in the national scientific and technological innovation system. It is of great significance for our country to build an innovative country and to implement the strategy of rejuvenating the country through science and education. Through the horizontal comparison of the scientific and technological innovation ability of colleges and universities, it is helpful for colleges and universities to recognize their own advantages and disadvantages, and to promote the educational departments and universities to allocate public scientific and technological resources more scientifically and reasonably, and to improve the efficiency of the use of funds. It is of great practical significance to promote the scientific and standardized management of science and technology in colleges and universities.
\end{abstract}

\section{Introduction}

At present, the ability of science and technology innovation has become the leading factor in the economic and social development of each country and has gradually become one of the main factors that determine the future and destiny of the country.

The national science and technology innovation system is the basic force to support the national innovation ability construction, and the university is one of the main bodies of the national science and technology innovation system.As an important means to improve the scientific and technological innovation ability of colleges and universities, the evaluation on scientific and technological innovation ability of colleges and universities can help to grasp the nature and law of scientific and technological innovation activities in colleges and universities. At the same time,only by constructing a scientific and reasonable evaluation index system of the scientific and technological innovation ability of colleges and universities, and strengthening the evaluation research of the scientific and technological innovation ability and efficiency of colleges and universities, can we better promote the scientific and technological innovation ability of colleges and universities.

\section{The Connotation of Scientific and Technological Innovation Ability in Colleges and Universities}

The evaluation of scientific and technological innovation ability in colleges and universities is a complex system engineering, and the understanding of its connotation is the most important problem to be considered in the comprehensive evaluation. By consulting the data, it is found that the previous researches are mainly focused on the following three aspects:

1. From the perspective of innovative resource demand and innovative achievements, the scientific and technological innovation in colleges and universities is regarded as an organic whole composed of various elements. In the whole innovation system, colleges and universities undertake the functions and tasks of knowledge production and dissemination, technological innovation and 
transformation as well as personnel training. According to the relationship between innovation elements, the scientific and technological innovation ability of colleges and universities is divided into basic strength of scientific and technological innovation, scientific and technological innovation input ability, knowledge innovation ability, technological innovation ability, scientific and technological innovation output ability. Science and technology innovation achievement transformation ability, talent innovation ability.

2. From the perspective of innovation process, the ability of scientific and technological innovation in colleges and universities is embodied in the process of knowledge creation, knowledge dissemination, transformation and diffusion of technological inventions. It also includes the technological, economic and managerial abilities that the university relies on in the process of scientific and technological innovation. Therefore, the scientific and technological innovation ability of colleges and universities can be divided into the input ability of scientific and technological innovation resources, the ability of scientific and technological innovation output and contribution. Science and technology innovation management ability and science and technology innovation support ability.

3. With the help of innovation system, scientific and technological innovation in colleges and universities is aimed at the knowledge creation and related technology development of basic science and technology science. An activity process and result of integrating the resources and functions of the main body of innovation elements. The constituent elements of the scientific and technological innovation system in colleges and universities are divided into the main body system and the supporting system, and the main body system includes the knowledge innovation system. Technological innovation systems. Support systems have funds, talent, information, public knowledge and technical support systems.

The above research has made the beneficial discussion from different angle to the connotation of university science and technology innovation ability. The university science and technology innovation is not only the key link which enhances the university school level, but also an important factor to realize the sustainable development of colleges and universities. The evaluation index system of scientific and technological innovation ability in colleges and universities should cover all aspects such as scientific research, talent training and social services. It runs through the whole process of scientific and technological innovation in colleges and universities.

\section{Evaluation Index System Construction}

Scientific and technological innovation ability is a complex concept. To describe it comprehensively and accurately, a series of indicators are needed to characterize its internal structure. These indexes should not only form a complete system to reflect the ability of scientific and technological innovation in a scientific and comprehensive way, but also be able to obtain statistical information conveniently and adopt an appropriate evaluation model in order to measure and compare the ability of science and technology innovation in colleges and universities. The establishment of a scientific and reasonable index system can make us well aware of the present situation of scientific and technological innovation ability of colleges and universities, providing reference for relevant departments to formulate effective science and technology policies, and provide the basis for optimizing the allocation of science and technology resources in colleges and universities, so as to promote the improvement of scientific and technological innovation ability of colleges and universities.

Based on the understanding of the connotation of scientific and technological innovation ability in colleges and universities, it follows the basic principles of scientific nature, comprehensiveness, relativity, comparability, guidance and feasibility of the construction of the index system. In this paper, AHP is used to construct a hierarchical evaluation index system which combines qualitative and quantitative indicators. The evaluation index system is divided into 5 evaluation modules and 10 evaluation items, 34 evaluation indicators.In the selection of specific indicators, the evaluation expert 
group is composed of academic personnel and well-known experts and scholars in this research field, and the weight of each index is determined by the way of experts scoring. As shown in Table 1.

Table 1. Evaluation index system of scientific and technological innovation ability in colleges and universities

\begin{tabular}{|c|c|c|c|c|c|}
\hline Primary indicator & weight & Ssecondary indexes & weight & Tertiary index & weight \\
\hline \multirow{8}{*}{$\begin{array}{l}\text { Basic ability of science and } \\
\text { technology innovation }\end{array}$} & \multirow{8}{*}{0.20} & \multirow{4}{*}{ Human Resources } & \multirow{4}{*}{0.52} & Proportion of scientific research personnel to all teaching staff & 0.28 \\
\hline & & & & $\begin{array}{c}\text { Proportion of scientific research personnel with high } \\
\text { professional titles to the total number of scientific research } \\
\text { personnel }\end{array}$ & 0.25 \\
\hline & & & & Proportion of researchers with doctorate degrees & 0.26 \\
\hline & & & & $\begin{array}{l}\text { Proportion of scientific research personnel under } 45 \text { years of } \\
\text { age }\end{array}$ & 0.21 \\
\hline & & \multirow{4}{*}{ Research Platform } & \multirow{4}{*}{0.48} & Number of doctoral, master's, post-doctoral mobile stations & 0.27 \\
\hline & & & & $\begin{array}{c}\text { Number of key laboratories and engineering centres at the } \\
\text { provincial level and above }\end{array}$ & 0.25 \\
\hline & & & & $\begin{array}{c}\text { Number of production, university and research bases at the } \\
\text { provincial level and above }\end{array}$ & 0.24 \\
\hline & & & & Number of key disciplines at the provincial level and above & 0.24 \\
\hline \multirow{5}{*}{$\begin{array}{l}\text { Science and technology } \\
\text { innovation investment ability }\end{array}$} & \multirow{5}{*}{0.22} & \multirow{5}{*}{ Research projects and funding } & \multirow{5}{*}{1} & $\begin{array}{l}\text { Total funds for science and technology projects realized in that } \\
\text { year }\end{array}$ & 0.22 \\
\hline & & & & Total funding for projects over $¥ 1$ million & 0.20 \\
\hline & & & & $\begin{array}{c}\text { Funds for science and technology projects at or above the } \\
\text { provincial level }\end{array}$ & 0.21 \\
\hline & & & & Total R \& D funds & 0.19 \\
\hline & & & & Per capita R \& D research funds & 0.18 \\
\hline \multirow{14}{*}{$\begin{array}{l}\text { Science and technology } \\
\text { innovation output ability }\end{array}$} & \multirow{14}{*}{0.24} & \multirow{3}{*}{ intellectual property right } & \multirow{3}{*}{0.22} & Number of patent authorizations & 0.40 \\
\hline & & & & $\begin{array}{c}\text { Number of patents for licensed inventions as a proportion of } \\
\text { total number of patents granted }\end{array}$ & 0.30 \\
\hline & & & & Quantity of new products, new technologies, new processes & 0.30 \\
\hline & & \multirow{3}{*}{ Books and Papers } & \multirow{3}{*}{0.21} & Number of papers included in the three indexes (SCI, EI, SSCI) & 0.30 \\
\hline & & & & Number of 100 excellent doctoral theses obtained in China & 0.40 \\
\hline & & & & $\begin{array}{c}\text { Number of scientific research monographs published by } \\
\text { national level publishing houses }\end{array}$ & 0.30 \\
\hline & & \multirow{2}{*}{ Scientific research achievement award } & \multirow{2}{*}{0.21} & $\begin{array}{l}\text { Number of awards for scientific and technological } \\
\text { achievements at or above the provincial and ministerial levels }\end{array}$ & 0.46 \\
\hline & & & & $\begin{array}{l}\text { Proportion of scientific and technological achievements awards } \\
\text { of first prise at or above the provincial and ministerial level }\end{array}$ & 0.54 \\
\hline & & \multirow{3}{*}{ the commercialization of research findings } & \multirow{3}{*}{0.19} & $\begin{array}{c}\text { Transformation and industrialization of Scientific and } \\
\text { technological achievements and income from extension of } \\
\text { achievements }\end{array}$ & 0.34 \\
\hline & & & & $\begin{array}{c}\text { Number of industrialization and extension projects of scientific } \\
\text { and technological achievements }\end{array}$ & 0.33 \\
\hline & & & & Amount of technology transfer contract & 0.33 \\
\hline & & \multirow{3}{*}{ Scientific and technological talents training } & \multirow{3}{*}{0.17} & $\begin{array}{c}\text { The number of the scholars of the Yangtze River and the } \\
\text { academicians of Chinese Academy of Sciences and the Chinese } \\
\text { Academy of Engineering }\end{array}$ & 0.40 \\
\hline & & & & Number of graduate students graduated that year & 0.28 \\
\hline & & & & $\begin{array}{c}\text { Number of scientific and technological innovation teams at } \\
\text { provincial level and above }\end{array}$ & 0.32 \\
\hline \multirow{3}{*}{$\begin{array}{l}\text { Management ability of scientific } \\
\text { and technological innovation }\end{array}$} & \multirow{3}{*}{0.16} & \multirow{3}{*}{$\begin{array}{l}\text { Science and technology management } \\
\text { Conditions and efficiency }\end{array}$} & \multirow{3}{*}{1} & Proportion of managers to total scientific research staff & 0.30 \\
\hline & & & & $\begin{array}{l}\text { Number of scientific research managers invested in millions of } \\
\text { scientific research funds }\end{array}$ & 0.40 \\
\hline & & & & $\begin{array}{c}\text { Number of scientific research management documents and } \\
\text { measures }\end{array}$ & 0.30 \\
\hline \multirow{4}{*}{$\begin{array}{l}\text { International communication } \\
\text { and cooperation capacity }\end{array}$} & \multirow{4}{*}{0.18} & \multirow{4}{*}{$\begin{array}{l}\text { The form and strength of domestic and foreign } \\
\text { scientific and technological exchanges and } \\
\text { cooperation }\end{array}$} & & Attendance at international conferences & 0.25 \\
\hline & & & 1 & Number of papers exchanged at international conferences & 0.30 \\
\hline & & & 1 & Number of personnel studying abroad & 0.25 \\
\hline & & & & Number of trainees received & 0.20 \\
\hline
\end{tabular}

\section{The Basic Model of Multilevel Gray Relational Analysis}

The system of green building design is a gray system with incomplete information, where the multilevel gray correlation analysis method is adopted to carry out evaluation research, specifically using the method to analysis quantitatively the correlation degree between the two factors in the system. The basic idea is, the optimal index value of the evaluation scheme is used as each entity element $\mathrm{x} 0 \mathrm{k}$ of the reference series $\mathrm{X} 0$, and that each index of the evaluation scheme is taken as the entity element xik of the comparison series $\mathrm{Xi}$, and then the gray relational degree ri between the reference series and the comparison series can be calculated. According to the value of ri we can judge the closeness degree of each decision scheme and ideal scheme, and then the order of pros and cons with each evaluated scheme can be determined. 


\section{Constructing Reference Series}

The evaluation value of the No.k index of the No.i evaluated scheme is expressed by vik $(\mathrm{i}=1,2, \ldots, \mathrm{m} ; \mathrm{k}=1,2, \ldots, \mathrm{n}), \mathrm{V} 0$ represents the reference series, which is usually made up of the best value v0k in the $\mathrm{m}$ evaluated schemes, $\mathrm{v} 0 \mathrm{k}=\mathrm{Optimum}(\mathrm{vik})$, and then $\mathrm{V} 0=(\mathrm{v} 01, \mathrm{v} 02, \ldots, \mathrm{v} 0 \mathrm{k})$.

For a specific gray system (supposing the system has $m$ evaluation objects and $n$ evaluation indicators), the matrix exists as follows:

$$
\mathrm{V}=(\text { Vik }) \mathrm{m} \times \mathrm{n}=\left[\begin{array}{cccc}
V_{11} & V_{12} & \ldots & V_{1 \mathrm{n}} \\
V_{21} & V_{22} & \ldots & V_{2 n} \\
\mathrm{M} & \mathrm{M} & \mathrm{M} & \mathrm{M} \\
V_{m 1} & V_{m 2} & \ldots & V_{m n}
\end{array}\right]
$$

And then $\mathrm{V} 0=(\mathrm{V} 01, \mathrm{~V} 02, \cdots, \mathrm{V} 0 \mathrm{n})$, so the reference sequence $\mathrm{V} 0$ will can be constructed.

\section{Standardized Processing of Index Values}

In order to facilitate the comparison of each evaluation index, the index values are to be standardized according to the formula (1).

$$
\mathrm{Xik}=\frac{V_{i k}-\min _{i} V_{i k}}{\max _{i} V_{i k}-\min _{i} V_{i k}}
$$

After standardized treatment:

$$
\mathrm{X}=(\mathrm{Xik}) \mathrm{m} \times \mathrm{n}=\left[\begin{array}{rrrr}
X_{11} & X_{12} & \ldots & X_{1 \mathrm{n}} \\
X_{21} & X_{22} & \ldots & X_{2 n} \\
\mathrm{M} & \mathrm{M} & \mathrm{M} & \mathrm{M} \\
X_{m 1} & X_{m 2} & \ldots & X_{m n}
\end{array}\right]
$$

\section{Calculating Correlation Coefficient}

The sequence $\mathrm{Xi}=(\mathrm{Xi} 1, \mathrm{Xi} 2, \cdots, \mathrm{Xin})(\mathrm{i}=1,2 \ldots, \mathrm{m})$ is as a comparison sequence, and $\mathrm{X} 0=(\mathrm{X} 01$, $\mathrm{X} 02, \cdots, \mathrm{X} 0 \mathrm{n})$ as the reference sequence, $\zeta \mathrm{ik}$ represents the correlation coefficient, it can be calculated according to the formula (3) as follows.

$$
\zeta_{i k}=\frac{\min _{i} \min _{k}\left|X_{0 k}-X_{i k}\right|+\rho \max _{i} \max _{k}\left|X_{0 k}-X_{i k}\right|}{\left|X_{0 k}-X_{i k}\right|+\rho \max _{i} \max _{k}\left|X_{0 k}-X_{i k}\right|}
$$

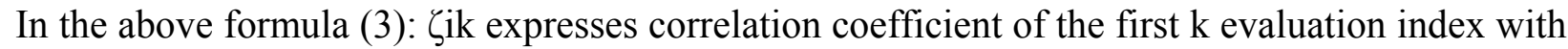
the comparison sequence $\mathrm{Xi}$ and the reference sequence $\mathrm{X} 0, \rho$ is resolution coefficient, $\rho \in$ $[0,1]$,generally $\rho=0.5$. So correlation coefficient matrix is as follows.

$$
\mathrm{E}=(\zeta \mathrm{ik}) \mathrm{m} \times \mathrm{n}=\left[\begin{array}{cccc}
\zeta_{11} & \zeta_{12} & \ldots & \zeta_{1 \mathrm{n}} \\
\zeta_{21} & \zeta_{22} & \ldots & \zeta_{2 \mathrm{n}} \\
\mathrm{M} & \mathrm{M} & \mathrm{M} & \mathrm{M} \\
\zeta_{m 1} & \zeta_{m 2} & \ldots & \zeta_{m \mathrm{n}}
\end{array}\right]
$$

\section{Calculating the Correlation Degree of Single Hiberarchy}

$\mathrm{W}$ represents the weight vector of a certain index layer relative to the previous one, $\mathrm{W}=(\mathrm{w} 1$, $\mathrm{w} 2, \ldots, \mathrm{wn})\left(\sum_{k=1}^{t} w_{k}=1, \mathrm{t}\right.$ is the total number of the index), and so the correlation degree $\mathrm{R}$ is as follows:

$$
\mathrm{R}=(\mathrm{ri}) 1 \times \mathrm{m}=(\mathrm{r} 1, \mathrm{r} 2 \ldots, \mathrm{rm})=\mathrm{WET}
$$




\section{Calculating the Final Correlation Degree}

Supposing that there is a multilevel system which has a total of L layers, the final gray correlation is calculated as follows: The correlation coefficient of the k-th layer index is calculated synthetically and it is obtained that the correlation degree of each index of the layer $(\mathrm{k}-1)$ of the system. And then, on the basis of the correlation degree of the layer, the previous layer (k-2) is continued to be synthesized, and so on, and finally the correlation degree of the highest level of the system will be found out, which is the ultimate correlation degree of the multilevel system. According to the size of the system's final correlation degree $\mathrm{ri}(\mathrm{i}=1,2, \ldots, \mathrm{m})$, you can determine the order of the pros and cons of each program, so as to achieve the purpose of schemes optimization.

\section{An Example}

In this paper, we want to evaluate the scientific and technological innovation ability of the five colleges and universities with V1, V2, V3, V4 and V5, and rank them in the order of high to the end.

\section{Calculation of Single Layer Correlation}

According to the evaluation index system mentioned above, five colleges and universities were scored by experts according to a 10 -point system, and each index value Vik $(\mathrm{i}=1,2 \ldots, 5 ; \mathrm{k}=1,2 \ldots 34)$ and the best value V0k of each index was obtained, and then the reference series V0 is available. At the same time, the correlation coefficient $\zeta \mathrm{ik}(\mathrm{i}=1,2,3,4,5 ; \mathrm{k}=1,2 \ldots, 34)$ is obtained as shown in Table 2 .

Table 2. Correlation coefficient values

\begin{tabular}{|c|c|c|c|c|c|}
\hline Correlation coefficient $\zeta_{\text {ik }}$ & $\mathrm{V}_{1}$ & $\mathrm{~V}_{2}$ & $\mathrm{~V}_{3}$ & $\mathrm{~V}_{4}$ & $\mathrm{~V}_{5}$ \\
\hline$\zeta_{\mathrm{i} 1}$ & 0.5 & 0.5 & 1 & $1 / 3$ & 1 \\
\hline$\zeta_{\mathrm{i} 2}$ & 1 & 0.5 & 0.5 & 1 & $1 / 3$ \\
\hline$\zeta_{\mathrm{i} 3}$ & 0.5 & 1 & 1 & $1 / 3$ & 0.5 \\
\hline$\zeta_{\mathrm{i} 4}$ & 1 & 0.5 & $1 / 3$ & 1 & 0.5 \\
\hline$\zeta_{\mathrm{i} 5}$ & 0.5 & 1 & 1 & $1 / 3$ & 0.5 \\
\hline$\zeta_{\mathrm{i} 6}$ & $1 / 3$ & 0.5 & 0.5 & 1 & 0.5 \\
\hline$\zeta_{\mathrm{i} 7}$ & $1 / 3$ & $1 / 3$ & 1 & $1 / 3$ & 1 \\
\hline$\zeta_{\mathrm{i} 8}$ & 0.5 & 0.5 & 1 & $1 / 3$ & 0.5 \\
\hline$\zeta_{\mathrm{i} 9}$ & 1 & $1 / 3$ & 0.6 & $3 / 7$ & 1 \\
\hline$\zeta_{\mathrm{i} 10}$ & 0.5 & $1 / 3$ & 0.5 & 0.5 & 1 \\
\hline$\zeta_{\mathrm{i} 11}$ & $1 / 3$ & 1 & $1 / 3$ & 1 & $1 / 3$ \\
\hline$\zeta_{\mathrm{i} 12}$ & $1 / 3$ & $1 / 3$ & 1 & $1 / 3$ & 1 \\
\hline$\zeta_{\mathrm{i} 13}$ & 1 & 1 & $1 / 3$ & 1 & $1 / 3$ \\
\hline$\zeta_{\mathrm{i} 14}$ & 0.5 & 1 & $1 / 3$ & 1 & 0.5 \\
\hline$\zeta_{\mathrm{i} 15}$ & $1 / 3$ & 1 & $1 / 3$ & 0.5 & 1 \\
\hline$\zeta_{\mathrm{i} 16}$ & 0.5 & 1 & $1 / 3$ & $1 / 3$ & 0.5 \\
\hline$\zeta_{\mathrm{i} 17}$ & 1 & $1 / 3$ & $1 / 3$ & 1 & $1 / 3$ \\
\hline$\zeta_{\mathrm{i} 18}$ & $1 / 3$ & 0.5 & 0.5 & 1 & $1 / 3$ \\
\hline$\zeta_{\mathrm{i} 19}$ & 0.6 & $3 / 7$ & 0.6 & $1 / 3$ & 1 \\
\hline$\zeta_{\mathrm{i} 20}$ & 0.5 & $1 / 3$ & 1 & $1 / 3$ & 0.5 \\
\hline$\zeta_{\mathrm{i} 21}$ & 0.5 & 1 & 0.5 & $1 / 3$ & 1 \\
\hline$\zeta_{\mathrm{i} 22}$ & $1 / 3$ & $1 / 3$ & 1 & $1 / 3$ & 1 \\
\hline$\zeta_{\mathrm{i} 23}$ & 1 & $1 / 3$ & 1 & $1 / 3$ & 1 \\
\hline$\zeta_{\mathrm{i} 24}$ & $1 / 3$ & 0.5 & 1 & $1 / 3$ & $1 / 3$ \\
\hline$\zeta_{\mathrm{i} 25}$ & $1 / 3$ & $1 / 3$ & 1 & $1 / 3$ & $1 / 3$ \\
\hline$\zeta_{\mathrm{i} 26}$ & $1 / 3$ & 0.5 & $1 / 3$ & 1 & 1 \\
\hline$\zeta_{\mathrm{i} 27}$ & 1 & 0.5 & $1 / 3$ & $1 / 3$ & $1 / 3$ \\
\hline$\zeta_{\mathrm{i} 28}$ & 1 & $3 / 7$ & $1 / 3$ & 1 & $3 / 7$ \\
\hline$\zeta_{\mathrm{i} 29}$ & 0.5 & 1 & 1 & $1 / 3$ & $1 / 3$ \\
\hline$\zeta_{\mathrm{i} 30}$ & $3 / 7$ & $1 / 3$ & $1 / 3$ & 0.6 & 1 \\
\hline$\zeta_{\mathrm{i} 31}$ & 0.6 & $3 / 7$ & $1 / 3$ & $1 / 3$ & 1 \\
\hline$\zeta_{\mathrm{i} 32}$ & $1 / 3$ & 1 & $1 / 3$ & 1 & 1 \\
\hline$\zeta_{\mathrm{i} 33}$ & 1 & $1 / 3$ & $1 / 3$ & 0.5 & 0.5 \\
\hline$\zeta_{\mathrm{i} 34}$ & 1 & $3 / 7$ & $1 / 3$ & 1 & 0.6 \\
\hline
\end{tabular}




\section{Multilevel Structural Correlation Degree Synthesis}

The correlation degree of each index in layer B can be obtained according to formula (5).

$$
\begin{aligned}
& R_{B_{1}}=W_{B_{1} C} \cdot E_{B_{1} C}^{T}=(0.28,0.25,0.26,0.21) \cdot\left[\begin{array}{ccccc}
0.5 & 0.5 & 1 & 1 / 3 & 1 \\
1 & 0.5 & 0.5 & 1 & 1 / 3 \\
0.5 & 1 & 1 & 1 / 3 & 0.5 \\
1 & 0.5 & 1 / 3 & 1 & 0.5
\end{array}\right] \\
& =(0.73,0.63,0.735,0.64,0.598)
\end{aligned}
$$

Similarly, it can be found that:

$$
\begin{gathered}
R_{B_{2}}=W_{B_{2} C} \cdot E_{B_{2} C}^{T}=(0.418,0.595,0.875,0.5,0.62) \\
R_{B_{3}}=W_{B_{3} C} \cdot E_{B_{3} C}^{T}=(0.633,0.593,0.552,0.648,0.74) \\
R_{B_{3}}=W_{B_{3} C} \cdot E_{B_{3} C}^{T}=(0.633,0.593,0.552,0.648,0.74) R_{B_{5}}=W_{B_{5} C} \cdot E_{B_{5} C}^{T}=(0.613,0.429,0.48,0.8,0.533) \\
R_{B_{6}}=W_{B_{6} C} \cdot E_{B_{6} C}^{T}=(0.5,0.693,0.73,0.333,0.77) R_{B_{7}}=W_{B_{7} C} \cdot E_{B_{7} C}^{T}=(0.533,0.278,1,0.333,0.78) \\
R_{B_{8}}=W_{B_{8} C} \cdot E_{B_{8} C}^{T}=(0.523,0.433,0.577,0.52,0.52) R_{B_{9}}=W_{B_{9} C} \cdot E_{B_{9} C}^{T}=(0.629,0.629,0.6,0.613,0.562) \\
R_{B_{10}}=W_{B_{10} C} \cdot E_{B_{10} C}^{T}=(0.7,0.576,0.333,0.708,0.795)
\end{gathered}
$$

Furthermore, the correlation degree of layer A can be obtained:

$$
\begin{aligned}
& R_{A_{1}}=W_{A_{1} B} \cdot E_{A_{1} B}^{T}=(0.52,0.48) \cdot\left[\begin{array}{ccccc}
0.73 & 0.63 & 0.735 & 0.64 & 0.598 \\
0.418 & 0.595 & 0.875 & 0.5 & 0.62
\end{array}\right] \\
& =(0.580,0.613,0.802,0.573,0.609)
\end{aligned}
$$

Similarly, it can be found that:

$$
R_{\mathrm{A}_{2}}=W_{\mathrm{A}_{2} B} \cdot E_{\mathrm{A}_{2} B}^{T}=(0.633,0.593,0.552,0.648,0.74)
$$

$$
\begin{gathered}
R_{A_{3}}=W_{A_{3} B} \cdot E_{A_{3} B}^{T}=(0.527,0.582,0.616,0.533,0.653) R_{A_{4}}=W_{A_{4} B} \cdot E_{A_{4} B}^{T}=(0.629,0.629,0.6,0.613,0.562) \\
R_{A_{5}}=W_{A_{5} B} \cdot E_{A_{5} B}^{T}=(0.7,0.576,0.333,0.708,0.795)
\end{gathered}
$$

Finally, the final correlation degree of each scheme can be obtained:

$$
\begin{aligned}
& R_{V}=W_{V A} \cdot\left[R_{A_{1}}, \quad R_{A_{2}}, R_{A_{3}}, R_{A_{4}}, R_{A_{5}}\right]^{T} \\
& =(0.2,0.22,0.24,0.16,0.18) \cdot\left[\begin{array}{ccccc}
0.58 & 0.613 & 0.802 & 0.573 & 0.609 \\
0.633 & 0.593 & 0.552 & 0.648 & 0.74 \\
0.527 & 0.582 & 0.616 & 0.533 & 0.653 \\
0.629 & 0.629 & 0.6 & 0.613 & 0.562 \\
0.7 & 0.576 & 0.333 & 0.708 & 0.795
\end{array}\right] \\
& =(0.608,0.597,0.586,0.611,0.674)
\end{aligned}
$$

\section{Ranking of Scientific and Technological Innovation Ability in Colleges and Universities}

According to the correlation degree in RV, the order of scientific and technological innovation ability of colleges and universities is as follows:

$$
\mathrm{V} 5>\mathrm{V} 4>\mathrm{V} 1>\mathrm{V} 2>\mathrm{V} 3 \text {. }
$$

\section{Conclusion}

Strengthening the comprehensive evaluation of the ability of scientific and technological innovation in colleges and universities is helpful to improve the level of scientific research and management, and the scientific rationality of the design of the evaluation index system is particularly critical. This paper analyzes the connotation of the ability of scientific and technological innovation in colleges and universities. Based on the principles of evaluation index system, this paper constructs the evaluation index system of science and technology innovation ability of colleges and universities, which includes 5 evaluation modules, 10 evaluation items and 34 evaluation indexes. And use expert consultation method to determine the weight of each evaluation index. Finally, through the selection of five universities as an example, the gray correlation analysis method is used to analyze and 
evaluate the scientific and technological innovation ability of the five colleges and universities quantitatively, to establish the order of superiority and inferiority, and to ensure the fairness and rationality of the evaluation results and provides a decision-making reference for carrying out this kind of work in the future. At present, there is a relative lack of quantitative analysis tools to evaluate the ability of scientific and technological innovation in colleges and universities. The comprehensive evaluation method based on gray correlation analysis is discussed in this paper, which can be said to be a very good innovation in this field of research.

\section{Acknowledgments}

The work described in the paper was supported by the Young Scholars Science Foundation of Lanzhou Jiaotong University with No.2016021, and by the Scientific Research Projects of University in Gansu Province with No.2016B-030.

\section{References}

[1]. He Zhiliang.Construction of Evaluation Index system of Scientific and technological Innovation ability in Colleges and Universities. Journal of Liaoning Industrial University (Social Science Edition), Vol.14(2010) No.2, p.23-26.

[2]. Liang Yan,Geng Yan,Lin Yuwei,etc.Research on Evaluation Index system of Scientific and technological Innovation ability in Colleges and Universities based on Analytic hierarchy process. Short theory journal, Vol.5(2009),p.194-196.

[3]. Wang Li,Yun Ling, Xu Chongqi.Application of Multi-level gray correlation Analysis in the selection of Green Building Design Scheme. Industrial Safety and Environmental Protection, Vol.42(2016) No.4, p.93-96.

[4]. Lan Xianglong,Xie Nanbin.Research on Evaluation Index system of Scientific and technological Innovation ability in Colleges and Universities based on AHP/DEA. Journal of Jiangxi normal University (Philosophy and Social Sciences Edition), Vol.43(2010) No.1, p.114-120.

[5]. Lu Fangyuan,Zhang Liping.Research on Evaluation Index System of Scientific and Technological Innovation in Colleges and Universities.Science and Technology Management Research,Vol.5(2010),p.51-53.

[6]. Wang Li,Yun Ling,Xu Chongqi,etc.Study on Highway Green Route selection based on Multi-level gray correlation Analysis. Highway engineering, Vol.41(2016) No.5, p.28-32.

[7]. Sun Yan,Yang Jian'an,Pan Pengfei,etc.Research on Evaluation Index system of Scientific and technological Innovation ability in Colleges and Universities. Research and development management, Vol.23(2011) No.3, p.125-129.

[8]. Lu Genshu,Liu Lei,Gu Lina.Research on the Evaluation of Scientific and technological Innovation ability in Colleges. University•Research and Evaluation, Vol.10(2017), p.57-63. 